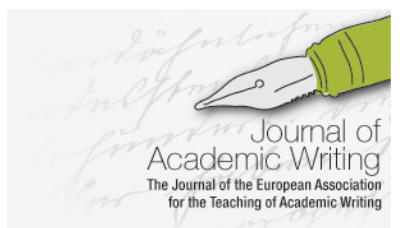

Journal of Academic Writing Vol. 8 No 1 Summer 2018, pages 121-130 http://dx.doi.org/10.18552/joaw.v8i1.359

\title{
Digital Tools in Academic Writing?
}

\author{
Dr. Miriam Schcolnik \\ Tel Aviv University, Israel
}

\section{Summary}

The process of writing has changed due to the increased availability of digital tools that can facilitate the task of writing in one's first language (L1) or second language (L2). There has been research on the use of tools by students writing in a foreign language, on the impact of digital tools on student writing, and on the use of digital tools for K-12 writing instruction. However, it seems no studies have investigated the use of digital tools by writing professionals. The aim of this exploratory study was to learn about the use of digital tools by writing professionals - researchers and instructors - when writing in first or second language. The results showed that some writing professionals use a variety of tools throughout the writing process, whereas others use very few tools, and that the patterns of use appear to be similar when writing in L1 or L2. The results informed a new categorization of tools, the various types and subtypes classified by purpose. The study offers a fresh perspective on the use of digital tools for writing by writing professionals.

\section{Dialogue}

We invite responses to this study with examples of the use of digital tools for writing and writing instruction. Case studies, short investigative papers and provocations will be collated and published in a future issue of the Journal of Academic Writing, as outlined in the submissions section of the journal. A fuller invitation is framed at the end of this article.

\section{Introduction}

Even though the organization and general features of academic genres, such as articles, theses, reports and reviews, have carried through from print to digital technologies, for many writers the process of writing has changed considerably as a result of the digital revolution. The increased availability of digital tools can facilitate the task of writing in first (L1) or second language (L2) for those who feel comfortable with the use of new tools and are willing to adopt them.

Technology offers new possibilities for accessing information, writing, and collaborating with others (Pennington 2013). Digital tools can help writers in all stages of the writing process, as they brainstorm, research, take notes, outline or map, draft, cite, rewrite and revise, add graphic elements, edit, share with colleagues and finally submit their manuscript for publication.

Many of us can remember what the process of writing looked like for most researchers thirty years ago. In order to review the literature, they had to sit in the library countless hours, many of which were spent at the microfiche reader and taking notes on paper. To search specialized databases, they had to consult printed books of abstracts or use the library's bibliographical database on laserdisc. To clarify language issues, they used printed thesauri and dictionaries. They probably used a text editing program to type their report and saved their work on floppy disks. They had to spend quite a lot of time formatting the text, and probably printed the first draft for proof-reading. They prepared their list of references 
manually, following the accepted format for their field of study. They then printed their report and usually shared it with colleagues for feedback. After final editing, they printed their report and mailed it to the journal.

The digital process probably looks quite different for most researchers. They may search for relevant literature in their library's online catalog or using a specialized search engine such as Google Scholar. They create their bibliographical database using a dedicated program such as EndNote. They may use a project management program that includes a word processor and other features such as a notepad and an outliner. They use online dictionaries and thesauri and may occasionally consult a machine translation program such as Google Translate, particularly when writing in a second language. If in doubt about a word's collocation, they may consult a concordance program, to see the word in context. They may also consult phrase banks to recruit suitable academic expressions for different sections of their paper. They probably create their charts using an online tool, and then share their document with colleagues using a file-sharing platform such as Google Drive or Dropbox. They finally submit their paper online.

What is meant by digital tools and other terms used, such as technologies, or resources? The use of these terms is not consistent in the literature. In general, digital tools is used to refer to programs (i.e., software) that have specific functionalities, such as spellcheckers. However, the term is sometimes used to refer to hardware, such as laptops or smartphones (Anderson and Mims 2014). Resources refers to materials or databases that provide information, such as guides, lists of links, tips or expressions, but from this study's participants' responses (see Appendix: question 7, 'Other'), it became clear to the author that they saw resources and research tools as digital tools, part of the writers' toolkit that can assist in the process of academic writing. The word technologies (Steel and Levy 2013) is used to refer to an assortment of tools, platforms and devices, such as course management systems, discussion forums, email, word processors, blogs, online dictionaries, communication software, translation software and concordancers. Due to the lack of uniformity in the use of these terms in the literature, and in view of the variety of tools mentioned by the survey participants, for this paper it was decided to use digital tool as an all-inclusive generic term that includes specific software tools, resources and platforms, but not hardware.

There has been research on the use of tools by students writing in a foreign language. Steel and Levy (2013), for example, conducted a survey of 587 foreign language students across ten languages at the University of Queensland in Australia. Their first objective was to record the technologies in use by language learners to support their language study and see what technologies students thought were beneficial to their language learning. They found that the students were well aware of the affordances of the technologies they were using, and that many technologies and applications had become normalized. Online dictionaries and translation software were the most commonly used (82-85\%) and were also perceived by the majority of students as beneficial to their language studies.

There has also been research on the impact of digital tools on student writing. For example, Purcell, Buchanan and Friedrich (2013) surveyed 2,500 Advanced Placement and National Writing Project teachers to measure perspectives on the impact of digital tools on student writing and writing instruction. Most teachers felt that digital technologies helped shape student writing and saw clear benefits, like the possibility of sharing work with others. This resulted in greater collaboration and more creativity and personal expression. Teachers felt digital tools encouraged students to invest more in their writing and they made teaching writing easier. However, they also saw some negative effects of the use of digital tools, such as the tendency to use informal writing in formal assignments, to write shorter texts, and in some cases to view digital tools as toys.

Anderson and Mims' comprehensive book (2014) on digital tools for K-12 writing instruction includes research as well as descriptions of instructional practice. Many of the chapters stress the importance of professional development and teacher education in the use of digital tools if teachers are to prepare students for $21^{\text {st }}$ century literacy demands. However, to the best of my knowledge, no studies have investigated the use of digital tools by writing professionals. 
Given the many and ever-growing affordances of technology, it is important to assess whether various populations are utilizing available tools in their work. The present study focuses on writing professionals, including writing instructors and writing researchers. Writing professionals deal with academic writing on a daily basis, not only teaching and assessing it, but also writing their own articles and reports. The study is motivated by a desire to find out what types of tools writing professionals use when writing, both in L1 and L2, and whether factors such as age, gender, and education affect frequency of use and variety of tools used. The information gathered about the types of tools used by writing professionals is meant to inform the development of a comprehensive taxonomy of tools.

Three main research questions guide the study:

1. Do writing professionals use digital tools?

2. What factors influence their use of digital tools?

3. What kinds of tools comprise the writer's toolkit?

\section{Method}

An email invitation to participate in the study was sent to the European Association of Teaching Academic Writing (EATAW) list and to the Israel Forum for Academic Writing (IFAW) list, with a link to the online survey (created in Google Forms). Overall, 103 writing professionals completed the survey (85 female and 18 male), with most participants (75) between the ages of 45 and 74 and with PhDs (62) or MAs (36). The native languages of the participants included Afrikaans, Arabic, Danish, Dutch, English, Estonian, French, German, Hebrew, Hungarian, Portuguese, Romanian, Russian, Serbian, Spanish, and Twi. The majority were speakers of English (54), followed by German (15) and Hebrew (13). Most participants (67) said their main activity was teaching, followed by 21 who said it was research.

Participants were asked to rate frequency of use of digital tools when writing formally in L1 and in L2 using a five-point Likert scale. A short list of tools was given, with an option to add other tools.

\section{Results}

Of the 103 participants, 50 said they write formally in both L1 and L2, so they rated frequency of use in both (see Fig. 1).

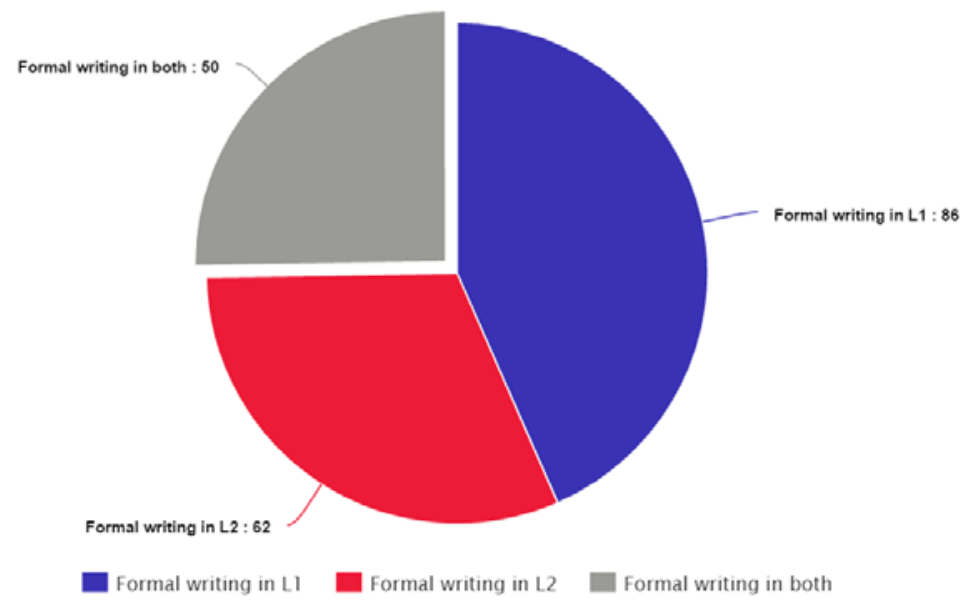

Figure 1. Languages Used for Formal Writing 


\section{Types of Tools}

Gillis and Marshall (2014) refer to genres of digital tools for teaching writing and classify the tools into five genres: defined network tools (e.g., email), social networks (e.g., Facebook), presentation tools (e.g., Prezi), summary/analysis tools (e.g., Wordle), and collaboration tools (e.g., Google Docs).

The categorization of types of tools developed in this article includes additional categories. Given the variety of tools mentioned by the participants, and the fact that their suggestions went far beyond the limited list offered in the survey questionnaire, it was decided to classify the tools into 8 main groups or categories by purpose, spanning all stages of the writing process from researching a topic to sharing the written product with others. The groups are: Resources, Research Tools, Organizational Tools, Prodding Tools, Language Tools, Design and Graphic Tools, Citation/Reference Tools and Collaboration Tools (Fig. 2). Most of the categories include subtypes. For example, language tools include spellcheckers, grammar checkers, concordancers, dictionaries, thesauri and machine translators.

\section{Types of Tools}

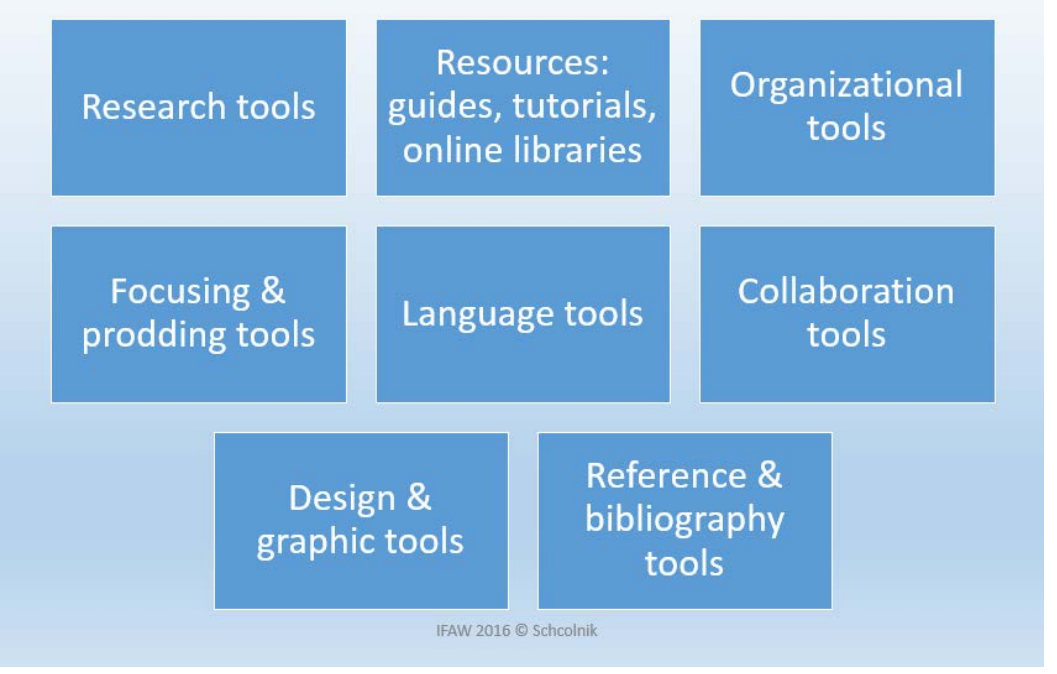

Figure 2. Types of Tools

Table 1 lists examples of the eight different types, many mentioned by the participants and others gathered from various online lists, such as Blackbourn (2015), Crouzier (n.d.), and Olinger (2016), among others. 
Table 1. Examples of Digital Tools for Writing

\begin{tabular}{|c|c|}
\hline Type & Subtypes and Examples \\
\hline Research tools & $\begin{array}{l}\text { Atlas.ti (http://atlasti.com) } \\
\text { MAXQDA (http://www.maxqda.com/) }\end{array}$ \\
\hline Resources & $\begin{array}{l}\text { 1. Search engines } \\
\text { Google (https://www.google.com/) } \\
\text { Google Scholar (https://scholar.google.com/) } \\
\text { 2. Online libraries } \\
\text { Google Books (https://books.google.com/) } \\
\text { JStor (http://www.jstor.org/) } \\
\text { 3. Writing guides } \\
\text { Colorado State University (http://writing.colostate.edu/quides/) } \\
\text { Harvard University } \\
\text { (http://writingproject.fas.harvard.edu/pages/writing-guides) } \\
\text { Purdue Online Writing Lab (https://owl.english.purdue.edu/) } \\
\text { 4. Handouts and phrase banks } \\
\text { Manchester Academic Phrasebank } \\
\text { (http://www.phrasebank.manchester.ac.uk/) } \\
\text { University of North Carolina (http://writingcenter.unc.edu/handouts/) }\end{array}$ \\
\hline $\begin{array}{l}\text { Organizational } \\
\text { tools }\end{array}$ & $\begin{array}{l}\text { 1. Mind mappers } \\
\text { Mural.ly (https://mural.ly/) } \\
\text { Mindmeister (https://www.mindmeister.com/) } \\
\text { FreeMind (http://freemind.sourceforge.net/wiki/index.php/Main Page) } \\
\text { Bubbl.us (https://bubbl.us/) } \\
\text { 2. Outliners } \\
\text { Microsoft Word } \\
\text { 3. Writing project managers } \\
\text { Evernote (https://evernote.com/?var=1) } \\
\text { Scrivener (https://www.literatureandlatte.com/scrivener.php) }\end{array}$ \\
\hline $\begin{array}{l}\text { Focusing and } \\
\text { prodding tools }\end{array}$ & $\begin{array}{l}\text { 1. Focus assistants } \\
\text { Calmly Writer (http://www.calmlywriter.com/online/) } \\
\text { OMM Writer (http://www.ommwriter.com/) } \\
\text { My Writing Spot (http://www.mywritingspot.com/) } \\
\text { Focus Writer (http://gottcode.org/focuswriter/) } \\
\text { 2. Prodding tools } \\
750 \text { Words (http://750words.com/) } \\
\text { The Most Dangerous Writing App } \\
\text { (http://www.themostdangerouswritingapp.com/) }\end{array}$ \\
\hline Language tools & $\begin{array}{l}\text { 1. Grammar checkers } \\
\text { Grammarly (https://www.grammarly.com/) } \\
\text { PaperRater (https://www.paperrater.com/) } \\
\text { Wordcounter (http://www.wordcounter.com/) } \\
\text { 2. Spellcheckers } \\
\text { PaperRater (https://www.paperrater.com/) } \\
\text { 3. Dictionaries } \\
\text { Dictionary.com (http://www.dictionary.com/) } \\
\text { 4. Thesauri } \\
\text { Thesaurus.com (http://www.thesaurus.com/) } \\
\text { 5. Concordancers } \\
\text { WebCorp (http://wse1.webcorp.org.uk/) } \\
\text { 6. Machine translation } \\
\text { Google Translate (https://translate.google.com/) }\end{array}$ \\
\hline
\end{tabular}




\begin{tabular}{|c|c|}
\hline $\begin{array}{l}\text { Collaboration } \\
\text { tools }\end{array}$ & $\begin{array}{l}\text { 1. File sharing platforms } \\
\text { Google Docs (https://docs.google.com/) } \\
\text { Dropbox (https://www.dropbox.com/) } \\
\text { Blogs } \\
\text { Tumblr. (https://www.tumblr.com/) } \\
\text { LiveJournal (http://www.livejournal.com/) } \\
\text { 3rack changes } \\
\text { MS Word } \\
\text { Google Docs (https://docs.google.com/) } \\
\text { 4. Screen capture tools } \\
\text { MS Snipping tool } \\
\text { Jing (https://www.techsmith.com/jing.html) }\end{array}$ \\
\hline $\begin{array}{l}\text { Design and } \\
\text { graphic tools }\end{array}$ & $\begin{array}{ll}\text { 1. } & \text { Infographics } \\
\text { Piktochart (https://piktochart.com/) } \\
\text { 2. Diagrams and Flowcharts } \\
\text { Gliffy (https://www.gliffy.com/) } \\
\text { Creately (http://creately.com/) }\end{array}$ \\
\hline $\begin{array}{l}\text { Reference and } \\
\text { bibliography } \\
\text { tools }\end{array}$ & $\begin{array}{l}\text { EndNote (http://endnote.com/) } \\
\text { Citation Machine (http://www.citationmachine.net/) } \\
\text { BibMe (http://www.bibme.org/) } \\
\text { Mendeley (https://www.mendeley.com/) } \\
\text { EasyBib (http://www.easybib.com/) }\end{array}$ \\
\hline
\end{tabular}

\section{Use of digital tools}

Since the list provided in the questionnaire included only four of the eight kinds of tools (classification done after data collection and based on the responses), and the option to add other tools did not offer the opportunity to rate frequency, the frequency results present a partial picture only (see Tables 2 and 3).

Table 2. Frequency of use in L1 and L2 for all participants

\begin{tabular}{|l|l|l|}
\hline All participants $\mathbf{- N}=\mathbf{1 0 3}$ & L1 & L2 \\
\hline Language tools & 3.2 & 2.7 \\
\hline Citation tools & 3.2 & 3.3 \\
\hline Organizational tools & 4.2 & 4.2 \\
\hline Graphic tools & 4.0 & 4.1 \\
\hline 1 = always 2 = often 3 = sometimes 4 = rarely 5 = never \\
\hline
\end{tabular}

Regarding the question whether there is a difference in use when writing in L1 or L2, the results showed that professionals who write in both L1 and L2 $(N=50)$ have similar patterns of use in both languages. 
Table 3. Frequency of use in L1 and L2 for those who write in both languages

\begin{tabular}{|l|l|l|}
\hline $\begin{array}{l}\text { Participants who write in 2 languages } \\
-\mathbf{N}=\mathbf{5 0}\end{array}$ & L1 & L2 \\
\hline Language tools & 3.2 & 3.5 \\
\hline Citation tools & 3.1 & 3.5 \\
\hline Organizational tools & 4.1 & 4.1 \\
\hline Graphic tools & 3.7 & 4.0 \\
\hline 1 = always 2 = often 3 = sometimes 4 = rarely 5 = never \\
\hline
\end{tabular}

Among the language tools listed, the most popular/frequently used, for both L1 and L2, is the spellchecker $-70 \%$ in L1 and $80 \%$ in L2 use the spellchecker always or often. The second most used for L2 is the dictionary - 70\% use it always or often. Unlike the finding in the Steel and Levy study, where the focus was on foreign language students (undergraduates aged 1721 ), in this survey the least popular language tool is machine translation (MT) $-82 \%$ in L1 and $63 \%$ in L2 said they rarely or never use MT.

A chi-square test was performed to determine whether participants' $(N=50)$ patterns of use of tools was similar when writing in L1 and L2. The results show a strong statistically significant relationship between: use of spellcheckers; grammar checkers; thesauri; machine translation; charts/diagrams; concordancers; and citation software in the two languages.

Regarding the factors that influence the use of digital tools among writing professionals, the results show that age, gender, education and main occupation do not. However, a strong relationship was found between L1 and use of language tools in L1. In fact, half of those who always use language tools in L1 are native speakers of English, and the other half are German speakers.

\section{Discussion}

A limitation of this study is that due to the lack of consistency in the literature in the use of terms referring to tools or technology, the author provided only a limited list of tools, excluding resources and research tools. As a result, it was not possible to assess frequency of use for those tools suggested by the respondents. Future surveys should include all eight types of tools, as well as subtypes with examples for clarification. This would surely yield more meaningful results. In spite of this limitation, the findings from this exploratory study highlight areas for further investigation into the type of digital tools used by instructors and researchers in the field of academic writing.

The results indicate that some writing professionals use a variety of tools all the time, for writing, research, organizing their ideas, illustrating, citing, and collaborating with others. Others use few tools only some of the time. One can infer that writers who take advantage of many tools regardless of the language they are writing in are power users. The Wikipedia (2017) definition of a power user (or an experienced user) is a computer user who employs advanced features of computer hardware, operating systems, programs, or web sites which are not used by the average user. Even though the survey did not assess participants' degree of digital literacy or use of digital tools for other purposes, from the findings it seems safe to assume that power users utilize digital tools regardless of the language they are writing in.

One might wonder why use of language tools was similar when writing in L1 and in L2. We need to assume that at least some of the participants in the survey are bilingual or even multilingual, hence just as comfortable in L2 as in L1. This could be a possible explanation. In 
addition, the phenomenon of language attrition (Seliger and Vago 1991) can also explain the need for language tools when writing in L1 where L1 is not the language used in everyday life. Regarding the popularity of different tools, the results showed that machine translation is the least popular language tool. This is the opposite of the finding in the Steel and Levy study (2013). This can probably be explained by two factors: the generational difference between the samples in the two studies, and the fact that the Steel and Levy sample consisted of foreign language students.

Regarding the finding that half of those who use digital tools in L1 are English speakers and the other half are German speakers, it is not possible to offer a valid explanation based on the results of the survey. One could hypothesize that speakers of English and German rely more on digital tools, perhaps due to language complexity, or that the educational systems encouraged them as students to use digital tools. It is possible that there are simply more tools available in those languages. This would constitute an interesting avenue for future research.

One of the goals of the current study was to determine what tools make up the writing professional's toolkit. The findings suggest that different writers have different toolkits, and there are many more digital tools than any writing professional is aware of or can possibly adopt. Writing professionals need to assess available tools so as to adopt those that can enhance both the process and the product of writing in both form and content.

\section{Invitation}

Since this is an exploratory study, it would be interesting to follow it up with an exchange of ideas in which the readers of JoAW could relate to the different issues introduced, in their own personal experience as academic writers or writing instructors. The discussion could also open new avenues for further research. The following are examples of issues discussants may want to tackle:

1. Can digital tools make the process of writing more efficient and the product more effective?

2. Does use of digital tools by instructors affect their teaching methodology? If so, how?

3. Should students be taught to use digital tools in their academic writing courses?

4. Do instructors feel that digital tools can benefit their students' writing? If so, what types of tools?

5. How should digital tools for writing be evaluated?

6. Should tools for writing be developed for other languages? 


\section{References}

Anderson, R.S. and Mims, C. (2014) Handbook of Research on Digital Tools for Writing Instruction in K-12 Settings. Hershey, PA: IGI Global

Blackbourn, N. (2015) 19 Digital Tools for Writing and Research. [online] available from $<$ http://nickblackbourn.com/digital-tools-for-writing-and-research/> $[22$ September 2017]

Crouzier, T. (n.d.) Digital Tools for Researchers. [online] available from $<$ http://connectedresearchers.com/online-tools-for-researchers/\#write>

[23 September 2017]

Gillis, V. and Marshall, M. (2014) 'Professional Development for Teaching Writing in a Digital Age'. in Handbook of Research on Digital Tools for Writing Instruction in K-12 Settings. ed. by Anderson, R.S. and Mims, C. Hershey, PA: IGI Global, 520-543

Olinger, A. (2016) '10 Tools All Academic Writers Should Be Aware Of'. [online] available from <http://www.teachercast.net/2016/03/01/10-tools-all-academic-writers-shouldbe-aware-of-by-anna-olinger/> [23 September 2017]

Pennington, M.C. (2013) 'Trends in Writing and Technology'. Writing and Pedagogy 5 (2), 155-179

Purcell, K., Buchanan, J. and Friedrich, L. (2013) The Impact of Digital Tools on Student Writing and How Writing is Taught in Schools [online] available from <http://pewinternet.org/Reports/2013/Teachers-technology-and-writing $\quad[22$ September 2017]

Seliger, H.W. and Vago, R.M. (1991) 'The study of first language attrition - An overview'. in First Language Attrition. ed. by Seliger, H.W. and Vago, R.M. Cambridge: Cambridge University Press, 3-16

Steel, C.H., and Levy, M. (2013) 'Language students and their technologies: Charting the evolution 2006-2011'. ReCALL 25 (3), 306-320

Wikipedia (2017) 'Power user'. [online] <https://en.wikipedia.org/wiki/Power_user> [23 September 2017] 


\section{Appendix. Digital Tools Survey}

This research deals with the use of digital tools for formal writing in both L1 and other languages. My target population is writing professionals, including, among others, writing instructors, researchers and teachers of language for academic purposes. The focus of the questionnaire is on the tools professionals use for writing rather than on those they use in writing instruction, although the two may coincide.

I would very much appreciate it if you would take a few minutes to answer the questions. Thank you very much for your contribution.

\section{Dr. Miriam Schcolnik - Tel Aviv University}

\section{Gender Male - Female}

2. Age 25-34 - 35-44 - 45-54 - 55-64 - 65-74 - 75 or older

3. What is the highest degree you have completed? $B A-M A-P h D$ or EdD - Other

4. What is your native language?

5. What is your main professional activity at present? Research - Teaching

6. Do you do any formal or academic writing in your native language? Yes - No If your answer to the above question is Yes, please go on to question 7. If your answer is No, please skip to question 8.

7. How often do you use these digital tools when writing in L1? Always - Often Sometimes - Rarely - Never

- Citation/bibliography software

- Concordances

- Dictionaries

- Flowcharting or diagramming software

- Grammar checkers

- Machine translation

- Mind mapping or outlining software

- Spellcheckers

- Thesauri

- Other

8. Please list any other digital tools you use in L1.

9. Do you do any formal or academic writing in other languages? Yes - No If your answer is Yes, please answer question 9.

10. How often do you use these digital tools when writing in other languages? Always - Often - Sometimes - Rarely - Never

- Citation/bibliography software

- Concordances

- Dictionaries

- Flowcharting or diagramming software

- Grammar checkers

- Machine translation

- Mind mapping or outlining software

- Spellcheckers

- Thesauri

- Other

11. Please list any other digital tools you use in other languages. 